\title{
Iraqi Power and U.S. Security in the Middle East
}

\author{
Stephen C. Pelletiere \\ Douglas V. Johnson II \\ Leif R. Rosenberger
}

1990

Strategic Studies Institute

U.S. Army War College

Carlisle Barracks, Pennsylvania 17013-5050 